\title{
Avaliação de Desempenho Organizacional: trajetória das pesquisas internacionais por meio de paradigmas e teorias
}

\author{
Evaluación del Desempeño Organizacional: trayectoria de las investigaciones internacionales por medio de \\ paradigmas y teorias \\ Organizational Performance Evaluation: Trajectory of the International Researches according to Paradigms \\ and Theories
}

Vinicius Abilio Martins

Universidade Federal de Santa Catarina, Brasil

viniciusabilio@gmail.com

ORCID: http://orcid.org/0000-0002-5668-5518

Sandra Rolin Ensslin

Universidade Federal de Santa Catarina, Brasil

ORCID: http://orcid.org/0000-0001-7420-8507

DOI: https://doi.org/10.11144/Javeriana.cc19-47.pado Redalyc: http://www.redalyc.org/articulo.oa?id=151556994005

Ademar Dutra

Universidade do Sul de Santa Catarina, Brasil

ORCID: http://orcid.org/0000-0001-5289-9482

\section{Resumo:}

3 A pesquisa sobre Avaliação de Desempenho Organizacional (ADO) pode ser influenciada por diferentes paradigmas científicos, e analisada por diferentes teorias. Essa diversidade direciona a pluralidade de pensamentos na agregação de valor ao conhecimento científico. Nesse sentido, esta pesquisa teve como objetivo caracterizar a trajetória das pesquisas internacionais quanto aos paradigmas científicos e às teorias adotadas na área de ADO. Para orientar os procedimentos da pesquisa, o instrumento de intervenção Knowledge Development Process-Constructivist (Proknow-C) foi selecionado, o que formou o Portfólio Bibliográfico com 31 artigos de cunho teórico e 39 de cunho empírico. Os resultados permitem inferir que as pesquisas na área da ADO não evoluíram em função nem dos paradigmas científicos que as informaram nem das teorias adotadas. Grande parte dos estudos, por ser informados pela abordagem Positivista, não apresentam novas propostas para atender às demandas de negócios/sociais atuais, mas sim busca agrupar e apresentar, de forma cronológica, a trajetória histórica da área e das medidas/modelos/sistemas e as emergências dessas demandas. Embora a utilização de teorias com 'olhares' institucional e individual se fez presente, seu uso para a amplitude da ADO e sua consorciação com teorias advindas de outras áreas de conhecimento ainda são incipientes.

Palavras-chave: Avaliação de Desempenho Organizacional, ADO, Paradigmas Científicos, Teorias científicas, ProKnow-C .

\section{Resumen:}

La investigación sobre Evaluación del Desempeño Organizacional (ADO) puede estar influenciada por diferentes paradigmas científicos y analizada por diferentes teorías. Esta diversidad evidencia la pluralidad de pensamientos en la agregación de valor al conocimiento científico. En ese sentido, esta investigación tuvo como objetivo caracterizar la trayectoria de las investigaciones internacionales en cuanto a los paradigmas científicos y las teorías adoptadas en el área de la ADO. Para orientar los procedimientos de investigación, se seleciono el instrumento de intervención Knowledge Development Process-Constructivist (Proknow-C), lo que conformó el Portafolio Bibliográfico con 31 artículos de cuño teórico y 39 de cuño empírico. Los resultados permiten inferir que las investigaciones en el área de la ADO no evolucionaron en función ni de los paradigmas científicos que las informaron ni de las teorías adoptadas. Gran parte de los estudios, por ser informados por su enfoque positivista, no presentan nuevas propuestas para atender las demandas de asuntos/sociales actuales, pero si busca agrupar y presentar, de forma cronológica, la trayectoria histórica del área y las medidas/modelos/sistemas y las emergencias de estas demandas. Aunque el uso de teorías con 'miradas' institucional e individual se hace presente, su uso para la amplitud de la ADO y su asociación con teorías advenidas de otras áreas de conocimiento todavía son incipientes.

Palabras clave: Evaluación del Desempeño Organizacional, ADO, Paradigmas Científicos, Teorías científicas, ProKnow-C . 


\begin{abstract}
:
Research on Organizational Performance Evaluation (OPE) may be influenced by different scientific paradigms and analyzed under different theories. Such a diversity evinces the plurality of thoughts in the added value of the scientific knowledge. In this vein, this research aimed to characterize the trajectory of international researches regarding the scientific paradigms and theories adopted in the OPE field. To guide the research procedures, an intervention instrument was selected, the Knowledge Development ProcessConstructivist (Proknow-C), which allowed to make up the Bibliographic Portfolio including 31 theoretically-based articles and 39 empirically-driven articles. The results herein allow to infer that researches in the OPE field did not evolved according to the scientific paradigms informing them or the adopted theories. A great deal of studies, as informed by positivist approaches, do not provide new suggestions to cope with the demands of the current social issues. However, this work seeks to group them together and present chronologically the historic trajectory in this field, the measures/models/systems and the emerging events leading to those demands. Although there is some use of theories with both institutional and individual 'views', this use is still poor regarding the wide scope of the OPE and its connection to theories coming from other fields of knowledge.
\end{abstract}

Keywords: Organizational Performance Evaluation, scientific paradigms, scientific theories, ProKnow-C .

\title{
Introdução
}

A Avaliação (mensuração e gestão) de Desempenho é um fenômeno social pautado em um processo de quantificação com o objetivo de estimular a ação. Aqui, os comportamentos, organizacionais e individuais, são moldados pelos valores e percepções individuais e das comunidades nas quais o indivíduo opera (Bititci, Garengo, Dörfler \& Nudurupati, 2012; Bititci, Turner \& Begemann, 2000).

Quando analisada na visão contemporânea, a medição de desempenho compreende o uso de medidas financeiras e não financeiras ligadas à estratégia de negócios da organização ( Otley, 2001; Neely, Gregory \& Platts, 1995). Estas podem gerar consequências para o comportamento das pessoas, para as capacidades organizacionais e para o desempenho global organizacional (Franco-Santos, Lucianetti \& Bourne, 2012). O uso de sistemas de mensuração e de gestão de desempenho é frequentemente recomendado para facilitar a implementação da estratégia e melhorar o desempenho organizacional (Martins, 2015; Melnyk, Bititci, Platts, Tobias \& Andersen, 2014).

De forma geral e resumida, ao se analisarem as áreas que utilizam a Avaliação de Desempenho, podem ser identificadas três correntes de pesquisa principais, procedentes de diferentes disciplinas: i) perspectiva da Contabilidade, ii) perspectiva da Gestão de Produção e Operações e iii) perspectiva de Controle Estratégico e Negócios (Ghalayini \& Noble, 1996; Bititci et al., 2012; Franco-Santos et al., 2012; Pavlov \& Bourne, 2011).

Essa pluralidade de áreas, peculiar dos estudos organizacionais, faz com que a pesquisa em Avaliação de Desempenho Organizacional (ADO) apresente uma identidade múltipla; influenciada por diferentes paradigmas científicos que na sua vez direcionam a pluralidade de pensamento na agregação de valor ao conhecimento científico e que pode ser analisada por inúmeras teorias, ao contemplar diferentes fundamentações científicas para explicarem os fenômenos que pesquisam (Frezatti, Aguiar, Wanderley \& Malagueño, 2015; Franco-Santos et al., 2012; Munck \& Souza, 2010).

Sob uma perspectiva apresentada por Burrell e Morgan (1979) e Lukka (2010), o campo da teoria organizacional é formado por uma série de posições epistemológicas e ontológicas de base. Essas posições culminam em 'paradigmas sociológicos' que fundamentam as teorias organizacionais modernas (Caldas, 2005). Assim, os paradigmas em ciências sociais representam um modelo de categorização dos campos em pesquisa organizacional (Caldas, 2005). No campo da pesquisa em contabilidade e da Avaliação de Desempenho, os modelos e sistemas de ADO também podem ser informados por abordagem de racionalidade obtidos, ou mesmo derivados, de modelos em que o tomador de decisões incorpora valores e preferências (Dias \& Tsoukiàs, 2003).

Assim, pesquisas sobre a ADO podem operar em três vertentes. De um lado, com base no objetivismo, considera-se uma realidade estável, objetiva e orientada basicamente para o resultado em termos de eficácia. Por outro lado, pode-se passar pela compreensão do comportamento humano com base nos próprios pontos de vista daquele que atua, por meio de uma observação naturalista e subjetiva. Ou, por fim, pode-se chegar à 
visão de que existem profundas contradições estruturais e conflitos na sociedade, dos quais as pessoas precisam estar cientes e da mesma forma ser emancipadas (Burrell \& Morgan, 1979; Lukka, 2010).

Além disso, um considerável número de teorias tem sido utilizadas na literatura para explicar como as ferramentas, modelos e sistemas de Avaliação de Desempenho (AD) afetam o desempenho nas organizações (Franco-Santos et al., 2012). No entanto, a maior parte da pesquisa contábil de hoje direciona esforços apenas à busca de contribuições marginais, fazendo uso de uma estrutura teórica e/ou metodológica já existente, ou apenas de métodos de pesquisa já consolidados que são aplicados em distintos contextos organizacionais (Lukka, 2010).

Dessa forma, emerge a seguinte questão de pesquisa: Qual é o comportamento das pesquisas internacionais sobre a Avaliação de Desempenho Organizacional, no tocante aos paradigmas cientificos e teorias adotadas? Assim, este estudo tem por objetivo caracterizar a trajetória das pesquisas internacionais quanto aos paradigmas cientificos e teorias adotadas na área de Avaliação de Desempenho Organizacional. A justificativa desta pesquisa se dá pela necessidade de se conhecer a existência, ou não, da pluralidade de pensamento, pautado pela utilização dos paradigmas e teorias de pesquisa, no âmbito internacional, tanto em pesquisas teóricas quanto em empíricas sobre ADO.

\section{Metodologia da pesquisa}

A presente pesquisa explora de forma qualitativa o fragmento da literatura de estudos, teóricos e empíricos, sobre ADO. Por ter como dados de análise os artigos científicos (Portfólio Bibliográfico, PB) já publicados (dados secundários) em bases de dados, caracteriza-se como pesquisa bibliográfica.

Para a execução desta pesquisa, delineada sob a perspectiva Construtivista, o procedimento que orientou aos autores foi o Knowledge Development Process-Constructivist (Proknow-C). Trata-se de um processo estruturado e sistematizado que possibilita a construção de conhecimento sobre um determinado assunto, com base nos interesses, delimitações e escolhas científicas do pesquisador que o operacionaliza, em que se identificam oportunidades de pesquisa (Thiel, Ensslin \& Ensslin, 2017; Valmorbida \& Ensslin, 2017; Dutra, Ripoll-Feliu, Fillol, Ensslin \& Ensslin, 2015). O instrumento ProKnow-C é composto por quatro etapas: (i) Seleção do Portfólio Bibliográfico (PB), (ii) Análise Bibliométrica, (iii) Análise Sistêmica e (iv) Formulação de Perguntas e Objetivos de Pesquisa (Dutra et al., 2015; Lacerda, Ensslin \& Ensslin, 2014). Para o alcance do objetivo desta pesquisa, operacionalizaram-se as etapas (i), (ii) e (iv). Os resultados da operacionalização da etapa (i) são apresentados na Figura 1.

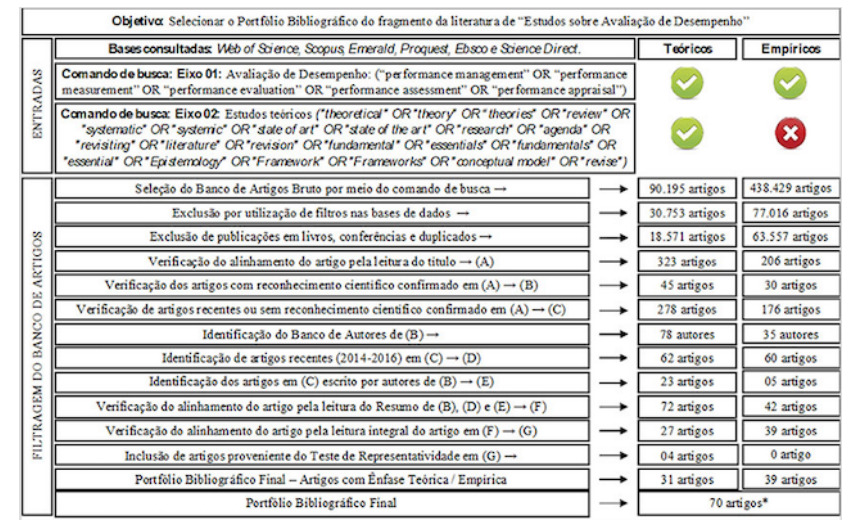

FIGURA 1.

Seleção do Portfólio Bibliográfico (PB) com base no ProKnow-C

Fonte: elaborado pelos autores

Por meio desse processo estruturado, 70 artigos compuseram o PB. Destes 31 eram artigos com ênfase em pesquisas teóricas (identificados com a marcação [T01] a [T31]) e 39, artigos empíricos (identificados com a marcação [E01] a [E39]), conforme a Tabela 1. Destaca-se que as coletas nas bases de dados foram feitas em setembro de 2016 (teóricos) e dezembro de 2016 (empíricos). Para os artigos com ênfase empírica foi utilizado somente o Eixo 01. 
TABELA 1.

Artigos do PB selecionados sobre Avaliação de Desempenho

\begin{tabular}{l|l|l|l}
\hline E01 & Ahrens \& Chapman (2002) & E21 & Hossain \& Prybutok (2016) \\
\hline E02 & Behery, Jabeen \& Parakandi (2014) & E22 & Hudson, Lean \& Smart (2001) \\
\hline T01 & $\begin{array}{l}\text { Berry, Coad, Harris, Otley \& Stringer } \\
(2009)\end{array}$ & E23 & Jääskeläinen \& Roitto (2016) \\
\hline E03 & Binder (2016) & E24 & Kang \& Shen (2016) \\
\hline E04 & Bititci (1995) & E25 & Kennerley \& Neely (2003) \\
\hline E05 & $\begin{array}{l}\text { Bititci, Mendibil, Martinez \& Albores } \\
(2005)\end{array}$ & T16 & Lebas (1995) \\
\hline E06 & $\begin{array}{l}\text { Bititci, Mendibil, Nudurupati, Garengo \& } \\
\text { Turner (2006) }\end{array}$ & E26 & Marafon, Ensslin, Lacerda \& Ensslin (2015) \\
\hline T02 & Bititci, Turner \& Begemann (2000) & E27 & MacAdam \& Bailie (2002) \\
\hline E07 & $\begin{array}{l}\text { Bititci, Turner \& Begemann (2000) } \\
\text { E08 }\end{array}$ & T17 & $\begin{array}{l}\text { Melnyk, Bititci, Platts, Tobias \& Andersen } \\
\text { (2014) }\end{array}$ \\
\hline T03 & $\begin{array}{l}\text { Bititci, Garengo, Dörfler \& Nudurupati } \\
(2012)\end{array}$ & T19 & Neely (1999) \\
\hline
\end{tabular}

TABELA 1. (CONT.)

Artigos do PB selecionados sobre Avaliação de Desempenho

\begin{tabular}{l|l|l|l} 
E09 & Bourne, Kennerley \& Franco-Santos (2005) & T20 & Neely (2005) \\
\hline T04 & $\begin{array}{l}\text { Bourne, Mills, Wilcox, Neely \& Platts } \\
(2000)\end{array}$ & T21 & Neely, Gregory \& Platts (1995) \\
\hline T05 & Broadbent \& Laughlin (2009) & T22 & $\begin{array}{l}\text { Neely, Richards, Mills, Platts \& Bourne } \\
(1997)\end{array}$ \\
\hline E10 & $\begin{array}{l}\text { Canonico, De Nito, Esposito, Martinez, } \\
\text { Mercurio \& Iacono (2015) }\end{array}$ & E28 & Nudurupati \& Bititci (2005), \\
\hline E11 & Carlsson-Wall, Kraus \& Messner (2016) & T23 & Nudurupati, Bititci, Kumar \& Chan (2011) \\
\hline T06 & $\begin{array}{l}\text { Carneiro-da-Cunha, Hourneaux Jr \& Corrêa } \\
(2016)\end{array}$ & E29 & Nudurupati, Tebboune \& Hardman (2016) \\
\hline E12 & Chenhall \& Langfield-Smith (1998) & T24 & Otley (1999) \\
\hline T07 & Choong (2014a) & T25 & Otley (2001) \\
\hline T08 & Choong (2014b) & T26 & Otley (2003) \\
\hline E13 & Dai, Kuang \& Tang (2016) & E30 & Valenzuela-Oyaneder \& Maturana- \\
& & & Valderrama (2016)
\end{tabular}


TABELA 1. (CONT.)

Artigos do PB selecionados sobre Avaliação de Desempenho

\begin{tabular}{l|l|l|l}
\hline E14 & De Waal (2003) & T27 & Pavlov \& Bourne (2011) \\
\hline E15 & De Waal (2007) & E31 & Pekkola \& Rantanen (2014) \\
\hline E16 & De Waal \& Coevert (2007) & E32 & Pekkola, Rantanen \& Saunila (2016) \\
\hline E17 & De Waal, Goedegebuure \& Geradts (2011) & E33 & Schneier, Shaw \& Beatty (1991) \\
\hline E18 & Decoene \& Bruggeman (2006) & E34 & Sharif (2002) \\
\hline T09 & Ferreira \& Otley (2009) & E35 & Sidorova, Arnaboldi \& Radaelli (2016) \\
\hline E19 & Flapper, Fortuin \& Stoop (1996) & T28 & Taticchi, Balachandran \& Tonelli (2012) \\
\hline T10 & Folan \& Browne (2005) & E36 & Thomas (2016) \\
\hline T11 & Franco-Santos \& Bourne (2005) & E37 & Tuomela (2005) \\
\hline T12 & Franco-Santos, Kennerley, Micheli, & T29 & Van Camp \& Braet (2016) \\
& $\begin{array}{l}\text { Martinez, Mason, Marr, Gray \& Neely } \\
\text { (2007) }\end{array}$ & & \\
\hline T13 & Franco-Santos, Lucianetti \& Bourne (2012) & E38 & Venkatesh \& Ramachandran (2014) \\
\hline T14 & Garengo, Biazzo \& Bititci (2005) & T30 & Waggoner, Neely \& Kennerley (1999) \\
\hline T15 & Ghalayini \& Noble (1996) & E39 & Wouters \& Sportel (2005) \\
\hline E20 & Haktanir \& Harris (2005) & T31 & Yadav, Sushil \& Sagar (2014) \\
\hline
\end{tabular}

Fonte: elaborado pelos autores.

A análise bibliométrica, segunda etapa do Proknow-C, tinha por objetivo gerar informações que viessem aprofundar o conhecimento sobre o tema (Dutra et al., 2015). Para tal, iniciou-se com a quantificação dos dados (contagem de ocorrência) das variáveis investigadas. Na sequência para os destaques das variáveis definidas, buscaram-se informações para legitimar o diagnóstico anteriormente identificado e para gerar e sustentar as argumentações que o pesquisador vai desenvolver (Thiel et al., 2017). Nesta pesquisa, foram investigadas as variáveis relacionadas aos paradigmas e às teorias científicas adotadas nos estudos.

Com relação ao paradigma científico, fez-se uso da classificação e noção propostas por Burrell e Morgan (1979) e Lukka (2010) para identificar qual paradigma informava cada estudo do PB. Para a classificação das pesquisas conforme os paradigmas em ciências sociais, foi utilizado o protocolo para pesquisas qualitativas (Creswell, 2014), conforme noções apresentadas na Tabela 2. Cabe salientar que não se trata do paradigma de afiliação do(s) autor(es), mas sim do qual foi enquadrado cada trabalho. 
TABELA 2.

Classificação quanto ao paradigma

\begin{tabular}{|c|c|}
\hline : & $\begin{array}{l}\text { i. Busca fornecer explicações essencialmente racionais para os fenômenos sociais, com base no objetivismo; } \\
\text { ii. Considera que todas as ciências podem aplicar métodos cientificos fundamentalmente semelhantes; } \\
\text { iii. Visa primordialmente descobrir regularidades semelhantes que são testáveis em dados sociais } \\
\text { (empiricos); } \\
\text { iv. Considera a realidade estável, objetiva e orientada basicamente para o resultado em termos de eficácia, } \\
\text { por meio de medição rigorosa e controlada; } \\
\text { v. Tem como propósito primordial formular leis gerais e encontrar um conjunto de proposições que traçam e } \\
\text { imponham as ações educativas. }\end{array}$ \\
\hline & $\begin{array}{l}\text { i. Compreende pesquisa subjetivista; } \\
\text { ii. Considera os significados subjetivos que os individuos atribuem às coisas; } \\
\text { iii. Reconhece o mundo como socialmente construido; } \\
\text { iv. Tem particular preocupação pela compreensão do comportamento humano com base nos próprios } \\
\text { valores, perspectiva e pontos de vista daquele que atua, por meio de uma observação naturalista e subjetiva; } \\
\text { v. Seu interesse focaliza o estudo dos significados e dos sentidos da interação humana. }\end{array}$ \\
\hline & $\begin{array}{l}\text { i. Resposta ao reducionismo da tradição positivista e ao conservadorismo do paradigma interpretativo; } \\
\text { ii. Pressuposto de que existem profundas contradições estruturais e conflitos na sociedade de que as pessoas } \\
\text { precisam estar cientes e do qual eles precisam ser emancipados; } \\
\text { iii. Considera insuficiente a análise do statu quo; } \\
\text { iv. Necessidade de interpretação empirica dos dados sociais com os contextos políticos e ideológicos em que } \\
\text { se geram as ações sociais. }\end{array}$ \\
\hline
\end{tabular}

Fonte: elaborado pelos autores, com base em Burrell e Morgan (1979) e Lukka (2010).

Com relação à variável "teorias", os autores, por meio da leitura integral dos artigos do PB, buscaram a manifestação explícita nos artigos da utilização de teoria(s) como backgroud das pesquisas. No caso de manifestação de utilização de teoria, os autores trouxeram para o texto a forma como esta se fez presente ou foi manifestada pelos pesquisadores dos artigos do PB. O intuito foi verificar a relação das teorias, em geral provenientes de outras áreas do conhecimento, com o tema da ADO e a contribuição apresentada. Adicionalmente, testar a admissibilidade da utilização de teorias de base por parte das vertentes de pesquisas teóricas e empíricas.

Como estratégia de validade na identificação das características da Tabela 2 que cada pesquisa apresentava, um dos autores, após a leitura, listou esses elementos. Na sequência, a listagem foi analisada e validada por outro autor "member checking" (p. 201) conforme a estratégia de validade proposta por Creswell (2014), a fim de verificar a precisão (accuracy) dos resultados.

\section{Referencial Teórico}

\section{Trajetória histórica da ADO}

A ADO, segundo literatura relacionada, pode ser dividida em dois momentos principais. No primeiro momento, cujo período vá do final de 1880 até a década de 1980 (Ghalayini \& Noble, 1996), a ênfase recaía, centralmente, sobre variáveis financeiras tradicionais da contabilidade, como rentabilidade, retorno 
dos investimentos, participação de mercado e produtividade (Ghalayini \& Noble, 1996; Yadav, Sushil \& Sagar, 2014).

$\mathrm{Na}$ década de 1930, foi proposto o Tableau de Bord, na França, que pretendia incorporar variáveis financeiras e não financeiras derivadas da missão e visão da organização. Já, na década de 1950, a General Electric utilizou um modelo de medição de desempenho com variáveis não financeiras (Carneiro-da-Cunha, Hourneaux \& Corrêa, 2016).

O segundo momento, cujo período vá da pós-década de 1980 até hoje, tem passado por alterações no entendimento de quais variáveis incorporar no sistema de $\mathrm{AD}$ das organizações, particularmente, devido às mudanças na natureza do trabalho (Neely, 1999), no mercado mundial (Yadav et al., 2014), no ambiente de negócios (Ghalayini \& Noble, 1996) e, em consequência, nas funções organizacionais (Neely, 1999).

A literatura recente, pós-1980, pode ser dividida em cinco fases. Uma primeira na década de 1980, onde o tema dominante centrava-se na discussão das falhas dos sistemas de medição de desempenho que se focalizavam apenas numa dimensão, incluindo aspectos como qualidade (Ghalayini \& Noble, 1996), satisfação do cliente (Bititci et al., 2012), satisfação do empregado e inovação, embora fossem além de somente incorporar as variáveis financeiras (Carneiro-da-Cunha et al., 2016) e apontassem informações para gestão de curto prazo, com consequências disfuncionais e impacto negativo associado à competitividade (Neely, 2005; Carneiro-da-Cunha et al., 2016).

A segunda fase, no início da década de 1990, direcionou o 'olhar' da área de AD aos sistemas de medição que considerassem as variáveis (financeiras e não financeiras) decorrentes da estratégia organizacional. Assim, sistemas de medição de desempenho, como o Balanced Scorecard, foram propostos por incorporarem variáveis/indicadores que pertenciam a mais de uma dimensão e que representavam a estratégia global da organização (Neely, 2005; Carneiro-da-Cunha et al., 2016).

A terceira fase, ao longo da década de 1990, envolveu a busca de maneiras como esses Balanced Scorecards poderiam ser usados, uma vez que variáveis de natureza distintas deveriam ser consideradas, conjuntamente, na etapa da mensuração do desempenho. Ou seja, os sistemas de medição de desempenho deviam incorporar e mensurar as diversas variáveis, representativas das várias dimensões que evidenciavam as estratégias organizacionais (Neely et al., 1995; Otley, 2001; Neely, 2005; Carneiro-da-Cunha et al., 2016). Essa fase direcionou esforços para o processo de "identificação de problemas" (p. 1271), o que reconheceu e discutiu os pontos fracos dos sistemas de medição e seu impacto organizacional (Neely, 2005). Além da área de AD, a área de gestão estratégica consolidou-se e passou a influenciar o 'olhar' da área de AD (Carneiro-da-Cunha et al., 2016).

A quarta fase, no início da década de 2000, reconheceu o fato de que os aspectos externos à organização deviam também ser considerados no sistema (Neely et al., 1995). Os modelos/sistemas devem considerar as necessidades e os objetivos das partes interessadas (clientes, fornecedores, empregados, acionistas, dentre outros), bem como os da organização (legitimidade organizacional). Com base nessa nova perspectiva, o sistema de ADO devia oferecer informações sobre a organização e sobre os aspectos ambientais, intangíveis, sociais e todos aqueles relacionados aos seus stakeholders (Carneiro-da-Cunha et al., 2016). Outro aspecto que passou a receber atenção da área referia-se a como usar e gerenciar as informações fornecidas pelos sistemas de ADO. Ou seja, a mensuração do desempenho não é o fim da $\mathrm{AD}$, mas, sim, um sistema que se complementa com o sistema de gerenciamento do desempenho (Lebas, 1995).

Nesse contexto, a partir de 2010, a área tem sido instigada a pensar em como lidar com os desafios decorrentes do contexto emergente e incorporá-los ou modificar a concepção dos sistemas de ADO, quais sejam, a gestão de desempenho interorganizacional, a Avaliação do Desempenho de empresas colaborativas e redes de organizações (Bititci et al., 2012).

Por isso, com base no conhecimento da trajetória da $\mathrm{AD}$, é possível entender e questionar os paradigmas e as teorias utilizadas nos estudos teóricos e empíricos de ADO. 


\section{Paradigmas e teorias na ciência social}

Os cientistas sociais, segundo Burrell e Morgan (1979), abordam os temas por meio de pressupostos, implícitos ou explícitos, relativos à natureza do mundo social e à maneira como eles podem ser investigados. Esses pressupostos, característicos das pesquisas nas ciências sociais e das pesquisas organizacionais, são provenientes de uma identidade múltipla, constituídos por diversas teorias e vertentes que contemplam diferentes fundamentações científicas para explicarem os fenômenos que pesquisam (Munck \& Souza, 2010).

Assim, Burrell e Morgan (1979) buscaram distinguir as diferentes abordagens encontradas nos estudos organizacionais e propuseram um quadro de referência que reflete uma série de pressupostos sobre a natureza do mundo social e a maneira como ele deveria ser investigado. Para Burrell e Morgan (1979), o campo de teoria organizacional seria formado por uma série de posições epistemológicas e ontológicas de base, as quais formariam algumas posições metateóricas a priori no desenvolvimento científico na análise organizacional. Essas posições culminariam em 'paradigmas sociológicos' que fundamentariam as teorias organizacionais modernas (Caldas, 2005). Observe-se que a noção de paradigma já havia sido cunhada por Thomas Kuhn, em 1962, em seu tratado 'A Estrutura das Revoluções Científicas' (Lukka, 2010).

Para Burrell e Morgan (1979), a ciência social pode ser conceituada em termos de quatro conjuntos de pressupostos relativos à ontologia, epistemologia, natureza humana e metodologia. Os pressupostos de natureza ontológica tratam à verdadeira essência do fenômeno sob investigação. O que deve estar claro aos pesquisadores é se a 'realidade' a ser investigada é uma externa ao indivíduo, onde esta é imposta à sua consciência a partir de fora, ou se esta é produto de sua própria consciência. Além, se é uma realidade de natureza objetiva ou produto da cognição do indivíduo.

Os pressupostos de natureza epistemológica se referem às bases do conhecimento (como o conhecimento é transmitido, é uma visão da própria natureza do conhecimento). Para Burrell e Morgan (1979), neste pressuposto, o pesquisador precisa ter ciência se o conhecimento é algo sólido, real e capaz de ser transmitido de modo tangível e adquirido pelo indivíduo, ou se é algo mais maleável, subjetivo, espiritual ou mesmo transcendental, com base na experiência e no insight de natureza única e essencialmente pessoal, o que necessita ser experimentado pessoalmente, e deve ser acumulado com base nas visões dos indivíduos pesquisados (Creswell, 2014), onde os conhecimentos de um indivíduo só podem ser adquiridos por suas próprias experiências.

Com relação aos pressupostos relacionados à natureza humana (implica a relação entre os seres humanos e seu ambiente), Burrell e Morgan (1979) afirmam que, num extremo, os seres humanos e suas experiências são vistos como produtos do ambiente em que são condicionados por suas circunstâncias externas. Num outro extremo, a perspectiva é que o homem é percebido como criador de seu ambiente, controlador em vez de controlado, senhor em vez de marionete (Burrell \& Morgan, 1979). Os indivíduos são vistos como seres intencionais, que dirigem sua energia psíquica e experiência de maneira que constituem o mundo de forma significativa e intencional (Morgan \& Smircich, 1980).

O último pressuposto relaciona-se com a metodologia. Cada conjunto de pressupostos anteriores tem consequências na maneira como se tenta investigar e obter 'conhecimento' do mundo social. A adoção dos pressupostos que correspondem com a metodologia está intimamente relacionada aos pressupostos anteriores. Assim, esses pressupostos são a base para a identificação dos pressupostos metodológicos, que irão culminar nos procedimentos adotados em cada pesquisa.

De forma didática, Burrell e Morgan (1979) propuseram uma classificação das pesquisas em ciências sociais em campos paradigmáticos (Caldas, 2005). Um paradigma refere-se a um corpo de ideias, assunções maiores, conceitos, proposições, valores e metas de uma área substantiva que influencia a maneira pela qual as pessoas observam o mundo, conduzem pesquisas científicas e aceitam formulações teóricas (Munck \& Souza, 2010).

Caldas (2005) e Burrell e Morgan (1979) sobrepuseram dois eixos: um representava os pressupostos metateóricos sobre a natureza da ciência, ao opor a ciência 'objetivista' com a ciência 'subjetivista', enquanto 
o outro simbolizava as premissas metateóricas sobre a natureza da sociedade, ao contrastar uma sociologia da 'regulação' com uma sociologia da 'mudança radical'. Dessa forma, os autores entendem ser os quatro principais paradigmas que fundamentariam, ou que poderiam fundamentar, a análise organizacional são o humanismo radical, o estruturalismo radical, o interpretativo e o funcionalista.

Esses quatro paradigmas oferecem uma maneira para identificar similaridades básicas e diferenças nos trabalhos de vários teóricos e, em particular, os quadros de referência subjacentes que eles adotam (Burrell \& Morgan, 1979).

Cada um desses quatro paradigmas, segundo Morgan (2005), representa uma rede de escolas de pensamento inter-relacionadas, diferenciadas em abordagem e perspectiva, mas que compartilham pressupostos fundamentais sobre a natureza da realidade que tratam (Munck \& Souza, 2010). Para entender o ponto de vista de cada paradigma, o pesquisador precisa estar consciente dos pressupostos que o compóem e das fronteiras com que cada paradigma é delimitado (Burrell \& Morgan, 1979).

O paradigma funcionalista, considerado o mainstream (Lukka, 2010) por orientar os estudos organizacionais de forma ampla, adota um ponto de vista objetivo e procura explicar as teorias de forma realista e determinista. Apresenta uma classificação pragmática, frequentemente orientada para o problema, o que vislumbra sempre as soluções práticas (Burrell \& Morgan, 1979). Considera que todas as ciências podem aplicar 'métodos científicos' semelhantes (Lukka, 2010), uma vez que pressupõem que a sociedade tem existência concreta e real e um caráter sistêmico orientado a produzir um estado de coisas ordenado e regulado (Munck \& Souza, 2010).

O comportamento dos indivíduos é visto como algo que está contextualmente 'ligado' a um mundo real de relacionamentos sociais concretos e tangíveis, que busca fornecer explicações essencialmente racionais para os fenômenos sociais, com base no objetivismo, que considera a realidade estável, objetiva e orientada basicamente para o resultado em termos de eficácia, por meio de medição rigorosa e controlada e que tem como propósito principal formular leis gerais e encontrar um conjunto de proposições que traçam e impõem as ações educativas (Caldas, 2005; Munck \& Souza, 2010; Lukka, 2010).

Os pressupostos ontológicos estimulam a crença na possibilidade de uma ciência social objetiva e isenta de conotações de valor, em que o cientista se distancia da cena que está analisando, e foca-se no rigor da técnica do método científico escolhido (Munck \& Souza, 2010). Para Lukka (2010), o paradigma funcionalista, quando é usado no estudo da ciência contábil, pode ser chamado de positivista.

As pesquisas classificadas no paradigma Interpretativista, ou Interpretativo, tem interesse em entender o mundo como ele é, sem deixar de entender a natureza fundamental do mundo social com experiências subjetivas. Compreende a pesquisa subjetivista, onde se consideram os significados subjetivos que os indivíduos atribuem às coisas (Burrell \& Morgan, 1979; Munck \& Souza, 2010; Lukka, 2010). Estas investigações podem ser modeladas por estudos históricos, literários e existenciais, nos quais o entendimento subjetivo dos indivíduos é significativo - central (Lourenço \& Sauerbronn, 2016).

Dessa forma, reconhece-se o mundo como uma construção coletiva por um processo social que emerge do que foi criado pelos indivíduos envolvidos, onde se tem particular preocupação com a compreensão do comportamento humano com base nos próprios valores, perspectiva e pontos de vista daquele que atua, por meio de uma observação naturalista e subjetiva; seu interesse focaliza o estudo dos significados e dos sentidos da interação humana (Lukka, 2010). A sociedade é entendida sob o ponto de vista do participante em ação, em vez da do observador. A base dos dados são os significados, de forma que significado precede lógica e fato (Lourenço \& Sauerbronn, 2016). O teórico social interpretativista tenta compreender o processo pelo qual as múltiplas realidades compartilhadas surgem, sustentam-se e se modificam (Munck \& Souza, 2010).

O paradigma humanismo radical, descrito por Burrell e Morgan (1979) como simpatizante da mudança radical, enfatiza como a realidade é socialmente criada e socialmente sustentada, mas vincula sua análise ao interesse em alguma coisa que pode ser descrita como uma patologia da consciência, pela qual os seres humanos se aprisionam dentro de fronteiras da realidade que eles mesmos criam e sustentam (Burrell \& 
Morgan, 1979; Munck \& Souza, 2010; Lukka, 2010). Este paradigma está envolvido por uma visão da sociedade que prega a importância de transcender as limitações dos arranjos sociais que nos cercam.

O quarto paradigma, estruturalismo radical, é esclarecido por Burrell e Morgan (1979) como uma mudança radical sob um ponto de vista objetivo. Assim como o paradigma humanismo radical, fundamenta-se na visão de que a sociedade é uma força potencialmente dominadora. No entanto, paradigma estruturalismo radical é vinculado a uma concepção materialista do mundo social, definido por estruturas sólidas, concretas e ontologicamente reais. Vê-se a realidade como uma coisa que existe por si, de uma forma independente de como é percebida e reafirmada pelas pessoas em suas atividades do dia a dia (Burrell \& Morgan, 1979; Munck \& Souza, 2010).

Para Lukka (2010) e Lourenço e Sauerbronn (2016), quando se estuda na ciência contábil, os paradigmas humanismo radical e estruturalismo radical podem ser agrupados em um só, chamado paradigma crítico. A abordagem crítica é modelada por estudos marxistas e interpretativos que incidem sobre os insights e julgamentos dos sujeitos (Lourenço \& Sauerbronn, 2016). Essa classificação, ao englobar os dois paradigmas relacionados à sociologia da mudança radical, tem como característica ser uma resposta ao reducionismo da tradição positivista e ao conservadorismo do paradigma interpretativista (Lukka, 2010).

Para essa abordagem há múltiplas realidades que são problemáticas, feitas por meio de comunicação distorcida. Os significados são encontrados na linguagem e no comportamento social e eles precedem a lógica e a verdade (Lourenço \& Sauerbronn, 2016). Há o pressuposto de que existem profundas contradições estruturais e conflitos na sociedade das quais as pessoas precisam estar cientes e das quais elas precisam ser emancipadas, considera insuficiente a análise do statu quo e há necessidade de interpretação empírica dos dados sociais com os contextos políticos e ideológicos em que se geram as ações sociais (Lukka, 2010). $\mathrm{O}$ resultado da pesquisa é o conhecimento que se insere no quadro interpretativo, que também serve com o objetivo de auxiliar a libertação, o entendimento pessoal e a emancipação das forças que limitam a independência racional dos indivíduos (Lourenço \& Sauerbronn, 2016).

A relação entre a teoria e a prática contábil também pode ser observada por meio dos paradigmas (Lourenço \& Sauerbronn, 2016). Quando se observa a pesquisa contábil sob a abordagem positivista, a contabilidade está preocupada com os meios e não os fins, e as estruturas institucionais existentes são aceitas como dadas. Quando se analisa sob a abordagem interpretativista, a teoria contábil busca explicar a ação e entender como a ordem social é produzida e reproduzida. Já quando se analisa sob a abordagem crítica, a teoria tem um imperativo crítico, em particular, a identificação e a remoção da dominação e das práticas ideológicas.

Nesse sentido, Franco-Santos et al. (2012) comentam que um considerável número de teorias tem sido utilizadas na literatura para explicar como as ferramentas, modelos e sistemas de $\mathrm{AD}$ afetam o desempenho global e outros fatores intermediários nas organizações. Para Frezatti et al. (2015), no ambiente europeu, essa ênfase pode decorrer de um foco em teorias organizacionais com base sociológica, enquanto, no caso norteamericano, parece sugerir a predominância de teorias econômicas, com destaque para a teoria de agência, e teorias baseadas em Psicologia.

\section{Resultados: Análise quanto aos paradigmas e às teorias científicas utilizadas}

\section{Paradigmas que informaram as pesquisas internacionais de ADO}

Em relação aos paradigmas, a Tabela 3 apresenta os resultados da classificação feita por meio da leitura e análise de conteúdo de cada um dos artigos do PB. Os parágrafos a seguir sumarizam os objetivos dos estudos para evidenciar o paradigma que os informaram. 
TABELA 3.

Classificação dos artigos teóricos e empíricos de ADO quanto ao paradigma

\begin{tabular}{|l|l|}
\multicolumn{2}{|c|}{ Teóricos } \\
\hline \multirow{2}{*}{ Positivista } & $\begin{array}{l}\text { T01, T03, T04, T06, T07, T08, T10, T11, T13, T14, T15, T17, T18, T19, T20, T21, T22, T23, } \\
\text { T24, T27, T28, T30, T31. }\end{array}$ \\
\hline Interpretativo & T02, T05, T09, T12, T16, T25, T26, T29. \\
\hline Crítico & - \\
\hline \hline & $\begin{array}{l}|c| \\
\text { Empíricos }\end{array}$ \\
\hline Positivista & E33, E34, E35, E36, E38. \\
\hline Interpretativo & E01, E02, E05, E06, E08, E09, E10, E11, E12, E16, E18, E26, E29, E30, E37, E39. \\
\hline Crítico & - \\
\hline
\end{tabular}

Fonte: elaborado pelos autores.

Pesquisas teóricas: dos 31 artigos teóricos, o paradigma positivista orientou a investigação de 21 deles (68\%). Este resultado concorda com o entendimento de Lukka (2010), em que as pesquisas sob a abordagem positivista se apresentam como dominantes na área contábil. Consequentemente, também se percebe isso na temática sobre AD. Além disso, nenhuma pesquisa teórica foi orientada pelo paradigma crítico.

Os trabalhos enquadrados nessa categoria buscaram apresentar levantamentos sobre o tema AD (Carneiroda-Cunha et al., 2016; Nudurupati, Bititci, Kumar \& Chan, 2011; Neely et al., 1995; Neely, 2005; Garengo, Biazzo \& Bititci, 2005; Folan \& Browne, 2005), propor frameworks (Taticchi, Balachandran \& Tonelli, 2012; Otley, 1999; Neely, Richards, Mills, Platts \& Bourne, 1997; Neely, 1999), propor modelos (Bititci et al., 2000; Choong, 2014a; Choong, 2014b), propor medidas (Ghalayini \& Noble, 1996), identificar a existência de relações entre variáveis de desempenho e explicações para o desempenho diagnosticado (Yadav et al., 2014; Pavlov \& Bourne, 2011; Franco-Santos, Kennerley, Micheli, Martinez, Mason, Marr, Gray \& Neely, 2007; Franco-Santos \& Bourne, 2005; Waggoner, Neely \& Kennerley, 1999; Neely, 1998) e identificar lacunas e agendas quanto ao futuro da área de AD (Melnyk et al., 2014; Bourne, Mills, Wilcox, Neely \& Platts, 2000).

Destacaram-se algumas das pesquisas acima enumeradas. Neely e os coautores que com ele trabalharam adotaram uma postura predominantemente positivista. O estudo de Neely et al. (1995) apresentou um levantamento de medidas de desempenho, relacionadas à qualidade, tempo, custos e flexibilidade, e apresentou questões centrais que devem ser consideradas na elaboração de um sistema de AD. Já Neely et al. (1997), em seu estudo, propuseram um framework para ajudar no processo de concepção e auditagem de medidas de desempenho, com base na literatura. Em 2005, Neely atualizou o trabalho de Neely et al. (1995) e apontou, como sugestão para futuras pesquisas, aspectos que contribuiriam para a área, especialmente na investigação empírica de conceitos teóricos fundamentais já apresentados.

Já Carneiro-da-Cunha et al. (2016) analisaram a literatura com o objetivo de explicar o desenvolvimento cronológico dos modelos da área que passaram a ter um 'olhar' diferente em termos de: foco, perspectiva, escopo, amplitude, natureza e agente. Folan e Browne (2005) também analisaram a literatura, mas delimitaram à área da cadeia de suprimentos, onde descreveram a evolução da atividade de medição de desempenho nessa área.

Sob um 'olhar' de medidas, Garengo et al. (2005) listaram aquelas relacionadas às micro e pequenas empresas. Bititci et al (2000) abordaram sobre o que é sistema de medição de desempenho dinâmico, enquanto Melnyk et al. (2014) alertaram sobre a necessidade de desenvolvimento de sistemas de ADO em 
ambientes voláteis que incorporassem a dinamicidade dos negócios atuais, alinhados ao que Bititci et al. (2000) propunham.

Quando analisaram a influência da AD nas organizações, Franco-Santos e Bourne (2005) apontaram quais poderiam ser os fatores que afetavam a capacidade de as organizações se gerenciarem por meio das métricas dos sistemas de medição de desempenho. Na mesma linha, Pavlov e Bourne (2011) descreveram o efeito que a mensuração do desempenho produz nas rotinas organizacionais.

Além destas, apesar de se apresentarem predominantemente positivistas, os autores demonstraram preocupação com contextos específicos, o que é típico nas pesquisas interpretativistas. Waggoner et al. (1999), mesmo sob um modelo de forças que ajudam a moldar os sistemas de medição de desempenho utilizados nas organizações, reconhecem que os sistemas não são simplesmente concebidos e implementados, mas que necessitam evoluir ao longo do tempo. Já Neely (1998) demonstrou direcionamento para uma visão interpretativista ao mencionar que a maneira na qual os dados de desempenho são coletados, analisados, revisados e postos em prática deve ser adaptada para os motivos nos quais o desempenho está sendo medido. No entanto, no intuito de pacificar o entendimento e apresentá-lo de forma generalizável, os autores reuniram, de forma prescritiva, os motivos de medição dos quatro grupos.

Em oposição às limitações apresentadas pelas pesquisas que adotam o paradigma positivista, surgem trabalhos que se pautam pelo paradigma interpretativista. Pode-se identificar a necessidade de entendimento da $\mathrm{AD}$ em contextos específicos, dentro de uma estrutura baseada em sistemas holísticos, pautado pela não generalização de modelos (Bititci et al., 2012; Ferreira \& Otley, 2009; Otley, 2003; Otley, 2001; Lebas, 1995), discussões sobre falhas dos sistemas de AD (Van Camp \& Braet, 2016) ou mesmo uma discussão crítica sobre modelos de AD e consequências de utilização desses modelos (Franco-Santos et al., 2012; Broadbent \& Laughlin, 2009).

Dentre os destaques, tem-se a pesquisa de Lebas (1995) como a mais antiga na área contábil, na abordagem interpretativista. $\mathrm{O}$ autor considerou que o desempenho é construído pelo sistema de gestão e pelos gerentes; onde o 'por que medimos?' não pode ser separado de quem são os usuários e o desempenho não pode ser definido objetivamente, mesmo em um contexto específico.

No trabalho de Otley (2003), foi apresentada uma retrospectiva simplificada, mas enriquecedora, de sua vida acadêmica e a relação com o tema da $\mathrm{AD}$, sob a visão interpretativista do tema. Foi possível identificar a pretensão de Otley em entender a $\mathrm{AD}$ em contextos específicos nos quais, em alguns casos, apresentaram tanto exemplos vividos pelo autor quanto exemplos relacionados aos modelos presentes na literatura. $\mathrm{O}$ autor também argumentou pela não generalização de modelos e pela construção de modelos que representassem a especificidade da organização a que o modelo se destina.

Ferreira e Otley (2009) apresentaram uma estrutura de sistemas de gestão de desempenho como ferramenta de pesquisa de uma forma mais holística. Foi perceptível um tom interpretativista dos autores no decorrer do trabalho, ainda que, em determinados momentos, afirmativas positivistas sejam detectadas. Na mesma linha, Van Camp e Braet (2016) discutiram e apresentaram motivos para as falhas dos sistemas de ADO nos três níveis: métrica, estrutura e gestão.

Destaca-se também a pesquisa de Broadbent e Laughlin (2009) que desenvolveu um modelo conceitual de Sistemas de Gestão de Desempenho (SGD) com insights relacionados aos trabalhos de Otley (1999), Ferreira e Otley (2005) e Ferreira e Otley (2009). Sob esse enfoque, ainda que as discussões fossem marcadas em alguns comentários com tons de crítica, os autores não atingiram os níveis adotados no paradigma crítico e mantiveram, dessa forma, um caráter interpretativo em sua pesquisa.

Diferentemente dos demais trabalhos em que Bititci figura como autor ou coautor, em Bititci et al. (2012), foi possível identificar traços caraterísticos interpretativistas. Para os autores, a medição e a gestão de desempenho são indiscutivelmente um fenômeno social, onde seu comportamento é moldado pelos sentimentos, valores e crenças dos indivíduos, a organização, a comunidade e a sociedade em que ela opera. 
Foi sugerido pelos autores que pesquisas futuras precisam adotar uma abordagem mais interpretativa para a compreensão da $\mathrm{AD}$ como um sistema social integrado, holístico e dentro do contexto sempre emergente.

Pesquisas Empíricas: Similar ao resultado encontrado nas pesquisas teóricas, a maior parte das investigações empíricas foi orientada pelo paradigma positivista. A Tabela 3 apresenta os resultados da classificação feita pela análise de conteúdo dos autores, na qual 23 dos 39 estudos (59\%) foram informados pelo paradigma positivista. Além disso, nenhuma pesquisa foi orientada sob o paradigma crítico.

Os trabalhos enquadrados sob o paradigma positivista buscaram apresentar ferramentas, técnicas e procedimentos relacionados à AD (Sharif, 2002; Hudson, Lean \& Smart, 2001; Bititci et al., 2000; Bititci, 1995; Schneier, Shaw \& Beatty, 1991), demonstrar práticas e fatores que levam à implantação e provar a evolução de um sistema de $\mathrm{ADO}$, a sua importância e as consequências do compromisso da alta administração com a AD (Sidorova, Arnaboldi \& Radaelli, 2016; Kang \& Shen, 2016; Jääskeläinen \& Roitto, 2016; Dai, Kuang \& Tang,2016; Binder, 2016; Pekkola \& Rantanen, 2014; Venkatesh \& Ramachandran, 2014; Pekkola, Saunila \& Rantanen, 2016; De Waal, Goedegebuure \& Geradts, 2011; Haktanir \& Harris, 2005; Nudurupati \& Bititci, 2005; De Waal, 2003; Kennerley \& Neely, 2003; MacAdam \& Bailie, 2002), além de apresentar modelos genéricos de AD (Hossain \& Prybutok, 2016; De Waal, 2007; Flapper, Fortuin \& Stoop, 1996).

Percebeu-se que alguns autores entendem que a adoção irrestrita de um único paradigma pode diminuir a contribuição para a ciência. Consequentemente, foi perceptível, em mais de um caso, a oportunidade de desenvolvimento de pesquisas com base em vários paradigmas. Abaixo, seguem os principais destaques.

O principal autor que se destaca no PB empírico é Umit Bititci, com seis pesquisas. Além desses números, o autor se destaca por não apresentar afiliação sob um único paradigma, pois transita entre os paradigmas positivista e interpretativista. Assim, dessas seis, três puderam ser enquadradas no paradigma positivista e três, no paradigma interpretativista, o que evidencia uma evolução de seus estudos para atender às demandas que se apresentam.

No artigo de 1995, Bititci buscava fornecer um conjunto de ferramentas, técnicas e procedimentos para a auditoria dos sistemas de medição de desempenho. $\mathrm{O}$ autor adotou uma postura descritiva ao relatar o trabalho realizado com ênfase para as ferramentas e técnicas utilizadas para a análise e modelagem de sistemas de AD. Na pesquisa de 2000, com Turner e Begermann, foi explorado o uso de ferramentas de gestão, baseadas na tecnologia da informação, a fim de garantir que o sistema de medição de desempenho de uma organização fosse integrado, eficiente e eficaz, embora os autores adotassem uma perspectiva descritivista. Já em 2005, Bititci apresentou duas pesquisas: uma com características positivistas e outra com características interpretativistas.

A primeira, de enfoque positivista e feita com Nudurupati, forneceu evidência empírica de que os sistemas de $\mathrm{AD}$, suportados por meio de plataformas de tecnologia da informação e utilizados com o compromisso da alta administração, iriam melhorar a identificação dos pontos fracos dos negócios na tomada de decisões proativas, melhoria contínua, transparência e visibilidade e no comportamento positivo das pessoas.

No entanto, a segunda pesquisa de Bititci, com Mendibil, Martinez e Albores (2005), demonstrou como um modelo para medir e gerenciar o desempenho de uma empresa, desenvolvido por meio de um estudo de caso, não deve ser generalizável para empresas de outros ramos. Dessa forma, o contexto específico das organizações deve ser considerado no modelo.

No ano de 2006, Bititci, Mendibil, Nudurupati, Garengo e Turner modelaram a relação dinâmica entre medição de desempenho, estilos de gestão e cultura organizacional a fim de desenvolver melhor a compreensão das relações causais entre essas três áreas. Um quadro socialmente construído para mapear a interação dessas áreas foi desenvolvido em cinco estudos de caso, onde foram então observadas, em relação ao ciclo de vida de aplicação, as alterações ao estilo de gestão e à estrutura organizacional ao longo do tempo. Em 2015, Bititci, Cocca e Ates analisaram como a estratégia visual e as técnicas de gerenciamento de desempenho afetavam as práticas de avaliação e gestão de desempenho das organizações. 
Andre De Waal, contrário de Bititci, apresentou um predomínio do paradigma positivista. De seus quatro trabalhos que compõem o $\mathrm{PB}$, apenas um se enquadra no paradigma interpretativista. Sob o paradigma positivista, em 2003, De Waal buscou identificar os fatores comportamentais que são responsáveis pela concepção e implementação de um sistema de gestão de desempenho por meio de um survey. Em 2007, propôs um método genérico aplicável a qualquer instituição, denominado "Ciclo de desenvolvimento de gestão estratégica de desempenho".

Ainda sob o viés positivista, De Waal (2011) junto com Goedegebuure e Geradts relataram os resultados de um estudo que explorou o impacto quantitativo da gestão de desempenho nos resultados de uma organização sem fins lucrativos. Apesar da maior parte das pesquisas ser de cunho positivista, em 2007, De Waal e Coevert analisaram e interpretaram o funcionamento e o impacto do uso de um novo sistema de gestão de desempenho de duas divisões comerciais de uma agência bancária.

Sai Nudurupati, terceiro autor de destaque do $\mathrm{PB}$ empírico, apresentou, nas duas pesquisas anteriores com Bititci, tanto o enquadramento positivista quanto o interpretativista. $\mathrm{O}$ autor conseguiu manter uma aparente harmonia entre esses paradigmas de pesquisa, similar ao ocorrido com Umit Bititci. Nudurupati, além das duas pesquisas com Bititci, em uma terceira pesquisa em 2016, junto com Tebboune e Hardman, explorou como os modelos e práticas de mensuração e gestão de desempenho devem ser transformados para serem resilientes e refletirem o progresso das economias digitais. Ao informar, nessa pesquisa pela abordagem interpretativa e ter em vista a postura dos autores no sentido de que as transformações (modelos e práticas) a serem realizadas devem observar os contextos específicos de cada organização.

Ao prosseguir com os artigos positivistas, Binder (2016) discutiu valores organizacionais e culturas da AD. Apresentou também um modelo padronizado para identificar se e como um determinado valor cultural pode influenciar o que são considerados 'bons' resultados de trabalho e qual comportamento será esperado para produzir esses resultados.

Além desses, num contexto mais atual, Sidorova, Arnaboldi e Radaelli (2016) buscaram trazer um contexto contemporâneo à pesquisa de $\mathrm{ADO}$, com o objetivo de investigar o impacto das mídias sociais nos sistemas de ADO, em termos de métodos de medição, indicadores de desempenho e uso.

Thomas (2016) forneceu uma visão respeito aos efeitos do feedback contábil (relatórios de contabilidade) sobre o esforço individual e motivacional. Apesar da utilização de teorias provenientes da psicologia, o autor apresentou uma clara afiliação teórica positivista ao utilizar experimentos condicionados com simulação do papel dos respondentes, isolando variáveis ambientais, não considerando o contexto da pesquisa e procedendo a análises por meio de inferência estatística, com resultados apenas de cunho descritivista.

Em contraponto às pesquisas sob a abordagem positivista -aquelas que se pautaram pelo paradigma interpretativista- foi possível a identificação de 16 dos 39 artigos presentes, no PB empírico (41\%). Essas pesquisas buscaram demonstrar que (i) as medidas e modelos de $\mathrm{AD}$ construídos não devem ser generalizáveis, mas construídos para um contexto específico, ad hoc (Nudurupati, Tebboune \& Hardman, 2016; Marafon, Ensslin, Lacerda \& Ensslin, 2015; Tuomela, 2005; Wouters \& Sportel, 2005; Bititci et al., 2005; Bourne, Kennerley \& Franco-Santos, 2005), (ii) a AD é socialmente construída e é influenciada por fatores como estilos de gestão, cultura organizacional, transição do ambiente da empresa, estratégia visual e técnicas de gerenciamento em cada contexto (Carlsson-Wall, Kraus \& Messner, 2016; Bititci et al., 2015; Behery, Jabeen \& Parakandi, 2014; De Waal \& Coevert, 2007; Decoene \& Bruggeman, 2006; Bititci et al., 2006; Ahrens \& Chapman; 2002; Chenhall \& Langfield-Smith, 1998) e (iii) a ADO precisa ser influenciada por fatores, aprendizagem organizacional, mudanças culturais da organização, estratégias organizacionais e competitividade (Valenzuela-Oyaneder \& Maturana-Valderrama, 2016; Canonico, De Nito, Esposito, Martinez, Mercurio \& Pezzillo iacono, 2015).

Como destaques, tem-se o estudo de Behery et al. (2014) que explorou as características e as questões relacionadas à transição de uma empresa de pequeno e médio porte, localizada nos Emirados Árabes Unidos, do sistema tradicional de gerenciamento de desempenho a um sistema mais moderno (Balanced Scorecard e 
Mapa Estratégico). O principal ponto de destaque foi o fato de os indicadores propostos levarem em conta os valores de quem toma decisões. Nesse sentido, há, no artigo, a preocupação da identificação do que é preciso ser avaliado pelos próprios tomadores de decisões, não se valendo do aporte teórico que a literatura pode oferecer.

Canonico et al. (2015) analisaram como e em que medida é possível interpretar um sistema de ADO como um mecanismo de controle típico ou, de uma forma mais inovadora, como ferramenta de aprendizagem (oportunidade para promover a aprendizagem na organização).

Marafon et al (2015) construíram um modelo para apoiar a gestão da pesquisa e desenvolvimento e auxiliar à decisão dos gestores. Os autores utilizaram uma abordagem construtivista multicritério desenvolvida para contextos em que há o reconhecimento da necessidade de expansão de conhecimento, compreensão e construção dos critérios de decisão para apoiar ao gestor sobre o problema.

Chenhall e Langfield-Smith (1998) exploraram o papel que a contabilidade gerencial tem desempenhado no desenvolvimento dos sistemas de medição de desempenho em cinco organizações que implementaram programas de mudança. Os autores, além de discutirem os cinco estudos de caso, verificaram os itens que se adentram em cada caso e propuseram uma justificativa para as divergências.

Com base nas pesquisas relatadas, argumenta-se que a ADO necessita ir além da adoção de uma afiliação positivista. Argumenta-se que seu sucesso advém do 'olhar' quanto ao 'que', 'como' e 'por que' medir e 'quando realimentar/ajustar' com base na perspectiva organizacional. Assim uma multiperspectiva, multicritério ou multidimensão, informada por uma visão interpretativista, leva em conta o contexto, os stakeholders, a organização e os que tomam decisões que explicitam os objetivos que refletem o que deve ser avaliado na organização, bem como os reflexos da aprendizagem gerada.

\section{Análise quanto à teorias utilizadas}

Com relação à análise das teorias que foram utilizadas como background para as pesquisas, a Figura 2 apresenta a cronologia da aplicação dessas teorias nos artigos presentes no PB. O primeiro ponto a se considerar é o fato do baixo número de artigos que buscam a discussão entre as teorias e o contexto da AD. Dos 31 artigos presentes no $\mathrm{PB}$ de artigos teóricos, apenas quatro apresentaram alguma discussão nesse sentido. Já no PB de artigos empíricos, dos 39 artigos, nove fizeram uso de alguma teoria.

A teoria mais utilizada nos estudos de ADO foi a teoria da contingência, presente em cinco dos 70 artigos, dos quais três eram teóricos e dois, empíricos. A primeira abordagem dessa teoria nos artigos do PB foi no estudo de Chenhall e Langfield-Smith (1998) [E12], intitulado. Nele, os autores exploram o papel que a contabilidade gerencial tem desempenhado no desenvolvimento de sistemas de $\mathrm{ADO}$, em cinco organizações que implementaram programas de mudança. Além disso, os autores analisam os fatores que influenciam o papel da contabilidade gerencial no desenvolvimento de medidas de desempenho no âmbito dos programas de mudança organizacional. A utilização da teoria da contingência é tangenciada, uma vez que o único momento em que os autores tratam diretamente da teoria é quando fazem uso das palavras de Dent (1991, apud Chenhall e Langfield-Smith, 1998): "como tal, o artigo contribui para o nosso apreço emergente do caminho em que a Contabilidade é utilizada nas organizações, utilmente, que complementa as abordagens mais quantitativas para investigação levada pelos teóricos de contingência” (p. 383) e, assim, permanecem omissos durante todo o trabalho.

Também sem que haja aprofundamento, mas apenas sob uma apresentação contextual histórica, Otley menciona a relevância da teoria da contingência em Otley (2001) [T11] e Otley (2003) [T12]. Otley (2001) afirma que, caso as pesquisas da contabilidade de gestão desejem recuperar a sua relevância, é necessário devotar esforços nos problemas reais enfrentados pelos gerentes nas organizações, ao construir sistemas de ADO para essas organizações específicas. Já em 2003, Otley apresentou um relato pessoal de seu envolvimento 
com a investigação de controle gerencial, ao mencionar sua transição de atuação para a gestão de desempenho das organizações com base em suas necessidades. Em ambos trabalhos, o autor menciona que essa perspectiva ad hoc organizacional pode ser contemplada pela teoria da contingência e fica surpreso pelo pouco uso dela no contexto da ADO.

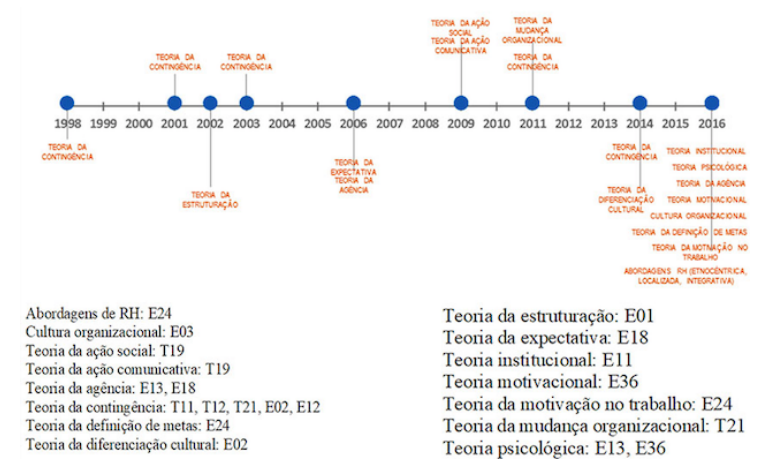

FIGURA 2.

Cronologia de uso das teorias em estudos de ADO

Fonte: elaborado pelos autores.

Behery et al. (2014) [E02] em sua pesquisa já comentada anteriormente, se utilizam tanto da teoria da contingência quanto da diferenciação cultural; no entanto não existe discussão dos 'ganhos' advindos da consideração dessas duas teorias.

Nudurupati et al. (2011), por meio dos conceitos da teoria da contingência e das teorias da mudança organizacional, apresentaram uma revisão bibliográfica sobre o papel do sistema de gestão da informação e gestão da mudança no ciclo de vida do sistema de ADO. Os autores também discutiram o sistema de ADO no contexto do ambiente de negócios emergentes, tais como globalização, servitização e criação de redes no contexto do ambiente multicultural.

A teoria da agência e a teoria psicológica também foram utilizadas nos estudos de ADO. Dai, Kuang e Tang (2016) realizaram dois experimentos para investigar como a ponderação diferente entre medidas objetivas e subjetivas, aferidas pelos gestores, afeta suas decisões.

Na mesma linha, Decoene e Bruggeman (2006) recorreram à teoria da agência e à teoria da expectativa para descrever a base teórica das relações entre alinhamento estratégico, motivação extrínseca e desempenho organizacional e ilustraram essa relação por meio de um modelo com base no Balanced Scorecard. Para os autores, a teoria da agência assume que os interesses dos superiores e subordinados são divergentes. Assim, superiores tentarão limitar a sua perda potencial de utilidade de comportamento oportunista dos subordinados por meio da implementação de sistemas de incentivos e monitoramento. Já por meio da teoria da expectativa, alinhada ao plano da remuneração, é esperado melhorar o desempenho organizacional.

O estudo de Thomas (2016) utilizou a teoria psicológica e a teoria motivacional para analisar as revisóes feitas nos sistemas de contabilidade gerencial. $\mathrm{O}$ autor forneceu uma visão dos efeitos do feedback contábil sobre o esforço individual e com base em teorias da psicologia, argumentou que o feedback pode aumentar ou diminuir o esforço continuado dos indivíduos, dependendo da motivação desenvolvida para o alcance das metas.

Aliados à área motivacional, Kang e Shen (2016) utilizaram aportes teóricos relacionados à teoria da motivação no trabalho, além da teoria da definição de metas e de abordagens de recursos humanos, com o objetivo de investigar as práticas de $\mathrm{AD}$ internacionais de empresas multinacionais sul-coreanas e a medida em que essas práticas são localizadas e/ou são etnocêntricas.

A teoria da estruturação foi abordada por Ahrens e Chapman (2002), em seu estudo longitudinal empírico dos sistemas de contabilidade, onde pesquisaram sua relação com a prestação de contas em uma cadeia de restaurantes, do Reino Unido. Com base na complexidade da ação social em torno de sistemas de medição de desempenho, o artigo apresentou evidências que sugerem que o uso de relatórios globais de desempenho, por parte dos gerentes das filiais, pode servir para disseminar a visão estratégica da matriz em unidades operacionais. Nesse contexto, os autores exploraram a inter-relação dos pilares da significação, legitimação e 
dominação (da teoria de estruturação) e evidenciaram uma diversidade de usos das medidas de desempenho entre a matriz e as filiais.

Carlsson-Wall et al (2016) examinaram o papel dos sistemas de medição de desempenho organizacional na gestão da coexistência de diferentes lógicas institucionais em uma organização de futebol e utilizaram a teoria institucional para identificar essas lógicas. Os autores destacaram como os resultados advindos das avaliações das medidas de desempenho afetam a forma como os compromissos entre as diferentes lógicas ocorrem. Complementaram argumentando que o entendimento desses compromissos, por vezes feitos em favor de uma lógica, e por vezes em favor da outra, poderá ocorrer pelo 'olhar' das informações promovidas pelas medidas de desempenho.

Binder (2016) descreveu uma abordagem para definir e comunicar as expectativas de desempenho em relação aos valores culturais da organização, por meio das teorias de cultura organizacional.

Broadbent e Laughlin (2009) desenvolveram um modelo conceitual de sistemas de ADO com base nos modelos de racionalidade, pautados pelas ideias de Max Weber e Jurgen Habermas sob as teorias da ação social e da ação comunicativa, embora, no modelo proposto, fiquem evidentes os insights dos trabalhos de Otley (1999), Ferreira e Otley (2005) e Ferreira e Otley (2009). Sob essas influências, os autores realizaram discussões com caráter interpretativo que, em vários trechos do trabalho, é marcado por tons de criticidade.

Em linhas gerais, os autores argumentaram que as pesquisas, na área da $\mathrm{ADO}$, não evoluíram em função dos paradigmas científicos que as informaram nem das teorias adotadas. A maioria dos estudos, por ser informados pelo paradigma positivista, não apresentam novas propostas para atender às demandas dos negócios, mercado ou mesmo as demandas sociais atuais. Buscam, no entanto, agrupar e apresentar de forma cronológica a trajetória histórica da área e das medidas, modelos, ferramentas, sistemas e emergências dessas demandas.

Embora a utilização de teorias com 'olhar' institucional e individual se fazem presentes, seu uso para a amplitude da $\mathrm{ADO}$ e consorciação com teorias advindas de outras áreas de conhecimento ainda são incipientes. Por fim, constata-se que as pesquisas, por meio dos paradigmas e das teorias, não acompanharam o foco evolutivo da ADO, conforme apresentado no referencial teórico.

\section{Considerações finais}

A discussão sobre a pluralidade de pensamento na agregação de valor ao conhecimento científico, no tocante à área da Avaliação de Desempenho Organizacional (ADO), pautada pelos paradigmas de pesquisa e teorias utilizadas nos estudos, permite a análise da trajetória histórica e percepção de como o tema pode ou pôde evoluir.

O objetivo deste trabalho foi caracterizar a trajetória das pesquisas internacionais quanto aos paradigmas cientificos e teorias adotadas na área de Avaliação de Desempenho Organizacional (ADO). Para atingir ao objetivo da pesquisa, o instrumento ProKnow-C foi utilizado. Identificou-se um Portfólio Bibliográfico (PB) composto por 31 artigos teóricos e 39 artigos empíricos. O processo de seleção do $\mathrm{PB}$, por meio do ProKnow$C$, se mostrou como uma ferramenta adequada, com metodologia clara e com rigor científico. $\mathrm{O}$ processo de busca apresenta, entre seus objetivos, a geração de informação relevante que minimize a aleatoriedade e parcialidade na seleção de conteúdos científicos. Apesar disso, o pesquisador é o agente central desse processo, pois a ferramenta, em seu caráter construtivista, apresenta, em algumas etapas, a possibilidade de influência de forma justificada nos resultados obtidos.

Em linhas gerais, quanto aos paradigmas, é perceptível que as pesquisas em ADO foram, predominantemente, informadas pela abordagem positivista em detrimento da interpretativista e da crítica, esta última com ausência de pesquisas no $\mathrm{PB}$ selecionado. Em termos qualitativos, argumenta-se a necessidade 
de estudos informados pelas abordagens interpretativista e crítica sob pena da área não evoluir e mesmo não atender às demandas de mercado e sociais já sinalizadas nos estudos e apontadas no referencial teórico.

Com relação ao background teórico, observa-se o baixo número de pesquisas que utilizaram essa base metodológica. Tal fato evidencia que, apesar da interação nas áreas de negócios, contabilidade e operações, a ADO faz pouco uso das bases teóricas advindas de áreas de conhecimento, tais como economia, sociologia, psicologia e comunicação, para explicar ou entender determinados comportamentos ou complexidades inerentes aos sistemas de ADO.

Este estudo não está livre de limitações, dentre elas destacam-se: (i) a restrição de artigos provenientes de bases de dados não selecionadas, (ii) a composição do PB apenas das publicações científicas em língua inglesa disponíveis gratuitamente na internet e (iii) a não operacionalização de todas as etapas do ProKnowC. Sugerem-se para futuras pesquisas: (i) a identificação das características bibliométricas e sistêmicas, em conformidade com a segunda e a terceira etapas do ProKnow-C, (ii) a investigação dos elementos constitutivos da $\mathrm{AD}$ para melhor comunicação entre os pesquisadores da área e (iii) a identificação de artigos que utilizem apenas teorias, a fim de evidenciar a influência de outras áreas no tema ADO.

\section{Referências}

Ahrens, T., \& Chapman, C. (2002). The Structuration of Legitimate Performance Measures and Management: Day-toDay Contests of Accountability in a UK Restaurant Chain. Management Accounting Research, 13(2), 151-171. https://doi.org/10.1006/mare.2001.0187

Behery, M., Jabeen, F., \& Parakandi, M. (2014). Adopting a Contemporary Performance Management System: A Fast-Growth Small-to-Medium Enterprise (FGSME) in the UAE. International Journal Productivity and Performance Management, 63(1), 22-43. https://doi.org/10.1108/IJPPM-07-2012-0076.

Berry, A. J., Coad, A. F., Harris, E. P., Otley, D. T., \& Stringer, C. (2009). Emerging Themes in Management Control: A Review of Recent Literature. British Accounting Review, 41(1), 2-20. https://doi.org/10.1016/j.bar.2008.09.001

Binder, C. (2016). Integrating Organizational-Cultural Values With Performance Management. Journal Organizational Behavior Management, 36(2-3), 185-201. https://doi.org/10.1080/01608061.2016.1200512.

Bititci, U. S. (1995). Modelling of Performance Measurement Systems in Manufacturing Enterprises. International Journal of Production Economics, 42(2), 137-147. https://doi.org/10.1016/0925-5273(95)00172-7

Bititci, U. S., Mendibil, K., Martinez, V., \& Albores, P. (2005). Measuring and Managing Performance in Extended Enterprises. International Journal Operations \& Production Management, 25(4), 333-353. https:// doi.org/10.1108/01443570510585534

Bititci, U. S., Mendibil, K., Nudurupati, S., Garengo, P., \& Turner, T. (2006). Dynamics of Performance Measurement and Organisational Culture. International Journal Operations \& Production Management, 26(12), 1325-1350. https://doi.org/10.1108/01443570610710579

Bititci, U. S., Turner, U., \& Begemann, C. (2000). Dynamics of Performance Measurement Systems. International Journal Operations \& Production Management, 20(6), 692-704. https://doi.org/10.1108/01443570010321676

Bititci, U., Cocca, P., \& Ates, A. (2015). Impact of Visual Performance Management Systems on the Performance Management Practices of Organisations. International Journal Production Research, 54(6), 1571-1593. https:// doi.org/10.1080/00207543.2015.1005770

Bititci, U., Garengo, P., Dörfler, V., \& Nudurupati, S. (2012). Performance Measurement: Challenges for Tomorrow. International Journal Management Reviews, 14(3), 305-327. https://doi.org/10.1111/ j.1468-2370.2011.00318.x

Bourne, M., Kennerley, M., \& Franco-Santos, M. (2005). Managing Through Measures: A Study of Impact on Performance. Journal Manufacturing Technology Management, 16(4), 373-395. https:// doi.org/10.1108/17410380510594480 
Bourne, M., Mills, J., Wilcox, M., Neely, A., \& Platts, K. (2000). Designing, Implementing and Updating Performance Measurement Systems. International Journal Operations \& Production Management, 20(7), 754-771. https:// doi.org/10.1108/01443570010330739

Broadbent, J., \& Laughlin, R. (2009). Performance Management Systems: A Conceptual Model. Management Accounting Research, 20(4), 283-295. https://doi.org/10.1016/j.mar.2009.07.004

Burrell, G., \& Morgan, G. (1979). Sociological Paradigms and Organisational Analysis. Elements of the Sociology of Corporate Life. London: Heinemann Educational Books.

Caldas, M. P. (2005). Paradigmas em estudos organizacionais: uma introdução à série. RAE-Revista de Administração de Empresas, 45(1), 53-57. http://dx.doi.org/10.1590/S0034-75902005000100008

Canonico, P., De Nito, E., Esposito, V., Martinez, M., Mercurio, L., \& Pezzillo iacono, M. (2015). The Boundaries of a Performance Management System Between Learning and Control. Measuring Business Excellence, 19(3), 7-21. https://doi.org/10.1108/MBE-04-2015-0021

Carlsson-Wall, M., Kraus, K., \& Messner, M. (2016). Performance Measurement Systems and the Enactment of Different Institutional Logics: Insights from a Football Organization. Management Accounting Research, 32, 45-61. https://doi.org/10.1016/j.mar.2016.01.006

Carneiro-da-Cunha, J. A., Hourneaux Jr, F., \& Corrêa, H. L. (2016). Evolution and Chronology of the Organisational Performance Measurement Field. International Journal Business Performance Management, 17(2), 223-240. https://doi.org/10.1504/IJBPM.2016.075553

Chenhall, R., \& Langfield-Smith, K. (1998). Factors Influencing the Role of Management Accounting in the Development of Performance Measures Within Organizational Change Programs. Management Accounting Research, 9(4), 361-386. https://doi.org/10.1006/mare.1998.0080

Choong, K. K. (2014a). Has this Large Number of Performance Measurement Publications Contributed to its Better Understanding? A Systematic Review for Research and Applications. International Journal Production Research, 52(14), 4174-4197. https://doi.org/10.1080/00207543.2013.866285

Choong, K. K. (2014b). The Fundamentals of Performance Measurement Systems: a Systematic Approach to Theory and a Research Agenda. International Journal Productivity and Performance Management, 63(7), 879-922. https://doi.org/10.1108/IJPPM-01-2013-0015

Creswell, J. W. (2014). Investigação Qualitativa e Projeto de Pesquisa-: Escolhendo entre Cinco Abordagens. São Paulo: Penso Editora.

Dai, N. T., Kuang, X., \& Tang, G. (2016). Differential Weighting of Objective versus Subjective Measures in Performance Evaluation: Experimental Evidence. European Accounting Review, 27(1), 1-20. https:// doi.org/10.1080/09638180.2016.1234402

De Waal, A. A. (2003). Behavioral Factors Important for the Successful Implementation and Use of Performance Management Systems. Management Decision, 41(8), 688-697. https://doi.org/10.1108/00251740310496206

De Waal, A. A. (2007). Successful Performance Management? Apply the Strategic Performance Management Development Cycle!. Measuring Business Excellence, 11(2), 4-11. https:// doi.org/10.1108/13683040710752698

De Waal, A. A., \& Coevert, V. (2007). The Effect of Performance Management on the Organizational Results of a Bank. International Journal Productivity and Performance Management, 56(5/6), 397-416. https:// doi.org/10.1108/17410400710757114

De Waal, A., Goedegebuure, R., \& Geradts, P. (2011). The Impact of Performance Management on the Results of a Non-Profit Organization. International Journal Productivity and Performance Management, 60(8), 778-796. https://doi.org/10.1108/17410401111182189.

Decoene, V., \& Bruggeman, W. (2006). Strategic Alignment and Middle-Level Managers' Motivation in a Balanced Scorecard Setting. International Journal Operations \& Production Management, 26(4), 429-448. https:// doi.org/10.1108/01443570610650576

Dias, L. C., \& Tsoukiàs, A. (2003). On the Constructive and Other Approaches in Decision Aiding. In Proceedings of the 57 th meeting of the EURO MCDA working group. 
Dutra, A., Ripoll-Feliu, V. M., Fillol, A. G., Ensslin, S. R., \& Ensslin, L. (2015). The Construction of Knowledge from the Scientific Literature About the Theme Seaport Performance Evaluation. International Journal Productivity and Performance Management, 64(2), 243-269. https://doi.org/10.1108/IJPPM-01-2014-0015

Ferreira, A., \& Otley, D. (2009). The Design and Use of Performance Management Systems: An Extended Framework for Analysis. Management Accounting Research, 20(4), 263-282. https://doi.org/10.1016/j.mar.2009.07.003

Ferreira, A., Otley, D., 2005. The Design and Use of Management Control Systems: An Extended Framework for Analysis. AAA Management Accounting Section Meeting Paper. https://doi.org/10.2139/ssrn.682984

Flapper, S. D. P., Fortuin, L., \& Stoop, P. P. M. (1996). Towards Consistent Performance Management Systems. International Journal of Operations \& Production Management, 16(7), 27-37. https:// doi.org/10.1108/01443579610119144

Folan, P., \& Browne, J. (2005). A Review of Performance Measurement: Towards Performance Management. Computers in Industry, 56(7), 663-680. https://doi.org/10.1016/j.compind.2005.03.001

Franco-Santos, M., \& Bourne, M. (2005). An Examination of the Literature Relating to Issues Affecting How Companies Manage Through Measures. Production Planning \& Control, 16(2), 114-124. https:// doi.org/10.1080/09537280512331333020

Franco-Santos, M., Kennerley, M., Micheli, P., Martinez, V., Mason, S., Marr, B., Gray, D. \& Neely, A. (2007). Towards a Definition of a Business Performance Measurement System. International Journal Operations \& Production Management, 27(8), 784-801. https://doi.org/10.1108/01443570710763778

Franco-Santos, M., Lucianetti, L., \& Bourne, M. (2012). Contemporary Performance Measurement Systems: Review of their Consequences and a Framework for Research. Management Accounting Research, 23(2), 79-119. DOI: 10.1016/j.mar.2012.04.001

Frezatti, F., Aguiar, A. B., Wanderley, C. A., \& Malagueño, R. (2015). A pesquisa em Contabilidade Gerencial no Brasil: Desenvolvimento, Dificuldades e Oportunidades. Revista Universo Contábil, 11(1), 47-68. http:// dx.doi.org/10.4270/ruc.2015147-68.

Garengo, P., Biazzo, S., \& Bititci, U. S. (2005). Performance Measurement Systems in SMEs: A Review for a Research Agenda. International Journal of Management Reviews, 7(1), 25-47. https://doi.org/10.1111/ j.1468-2370.2005.00105.x

Ghalayini, A. M., \& Noble, J. S. (1996). The Changing Basis of Performance Measurement. International Journal of Operations \& Production Management, 16(8), 63-80. https://doi.org/10.1108/01443579610125787

Haktanir, M., \& Harris, P. (2005). Performance Measurement Practice in an Independent Hotel Context: A Case Study Approach. International Journal Contemporary Hospitality Management, 17(1), 39-50. https:// doi.org/10.1108/09596110510577662

Hossain, M. M., \& Prybutok, V. R. (2016). Towards Developing a Business Performance Management Model Using Causal Latent Semantic Analysis. International Journal Business Performance Management, 17(2), 161-183. https://doi.org/10.1504/IJBPM.2016.075537

Hudson, M., Lean, J., \& Smart, P. A. (2001). Improving Control Through Effective Performance Measurement in SMEs. Production Planning \& Control, 12(8), 804-813. https://doi.org/10.1080/09537280110061557

Jääskeläinen, A., \& Roitto, J. M. (2016). Visualization Techniques Supporting Performance Measurement System Development. Measuring Business Excellence, 20(2), 13-25. https://doi.org/10.1108/MBE-09-2014-0032

Kang, H., \& Shen, J. (2016). International Performance Appraisal Practices and Approaches of South Korean MNEs in China. International Journal of Huma Resource Management, 27(3), 291-310. https:// doi.org/10.1080/09585192.2015.1039562

Kennerley, M., \& Neely, A. (2003). Measuring Performance in a Changing Business Environment. International Journal of Operations \& Production Management, 23(2), 213-229. https:// doi.org/10.1108/01443570310458465

Lacerda, R. T. D. O., Ensslin, L. \& Ensslin, S. R. (2014), Research opportunities in strategic management field: a performance measurement approach. International Journal Business Performance Management, 15(2), 158-174. https://doi.org/10.1504/IJBPM.2014.060165 
Lebas, M. J. (1995). Performance measurement and performance management. International journal of production economics, 41(1), 23-35. https://doi.org/10.1016/0925-5273(95)00081-X

Lourenço, R. L., \& Sauerbronn, F. F. (2016). Revistando possibilidades epistemológicas em contabilidade gerencial: em busca de contribuições de abordagens interpretativas e críticas no Brasil. Revista Contemporânea de Contabilidade, 13(28), 99-122. https://doi.org/10.5007/2175-8069.2016v13n28p99

Lukka, K. (2010). The Roles and Effects of Paradigms in Accounting Research. Management Accounting Research, 21(2), 110-115. DOI: 10.1016/j.mar.2010.02.002

Marafon, A. D., Ensslin, L., Lacerda, R. T. D. O., \& Ensslin, S. R. (2015). The Effectiveness of Multi-criteria Decision Aid Methodology: A Case Study of R\&D Management. European Journal Innovation Management, 18(1), 86-109. https://doi.org/10.1108/EJIM-10-2013-0106

Martins, V. A. (2015). Proposta de um mapa estratégico para uma universidade pública. Revista Evidenciação Contábil \& Finanças, 3(2), 88-103. DOI:10.18405/RECFIN20150206

McAdam, R., \& Bailie, B. (2002). Business Performance Measures and Alignment Impact on Strategy: The Role of Business Improvement Models. International Journal Operations \& Production Management, 22(9), 972-996

Melnyk, S. A., Bititci, U., Platts, K., Tobias, J., \& Andersen, B. (2014). Is Performance Measurement and Management Fit for the Future?. Management Accounting Research, 25(2), 173-186. DOI: 10.1016/j.mar.2013.07.007

Morgan, G. (2005). Paradigmas, metáforas e resolução de quebra-cabeças na teoria das organizações. RAE-Revista de Administração de Empresas, 45(1), 58-71. http://rae.fgv.br/rae/vol45-num1-2005/paradigmas-metaforas-resol ucao-quebra-cabecas-na-teoria-organizacoes

Morgan, G., \& Smircich, L. (1980). The case for qualitative research. Academy of Management Review, 5(4), 491-500. DOI: $10.2307 / 257453$

Munck, L., \& de Souza, R. B. (2010). Estudos organizacionais: uma relação entre paradigmas, metanarrativas, pontos de interseção e segmentações teóricas. Revista Pretexto, 11(2), 95-112. http://dx.doi.org/10.21714/ pretexto.v11i2.647

Neely, A. (1998). Three Modes of Measurement: Theory and Practice. International Journal Business Performance Management, 1(1), 47-64. https://doi.org/10.1504/IJBPM.1998.004544

Neely, A. (1999). The Performance Measurement Revolution: Why Now and What Next?. International journal of operations \& production management, 19(2), 205-228. https://doi.org/10.1108/01443579910247437

Neely, A. (2005). The Evolution of Performance Measurement Research: Developments in the Last Decade and a Research Agenda for the Next. International Journal Operations \& Production Management, 25(12), 1264-1277. https://doi.org/10.1108/01443570510633648

Neely, A., Gregory, M., \& Platts, K. (1995). Performance Measurement System Design: a Literature Review and Research Agenda. International Journal Operations \& Production Management, 15(4), 80-116. https:// doi.org/10.1108/01443579510083622

Neely, A., Richards, H., Mills, J., Platts, K., \& Bourne, M. (1997). Designing Performance Measures: A Structured Approach. International Journal Operations \& Production Management, 17(11), 1131-1152. https:// doi.org/10.1108/01443579710177888

Nudurupati, S. S., \& Bititci, U. S. (2005). Implementation and Impact of IT-Supported Performance Measurement Systems. Production Planning \& Control, 16(2), 152-162. https://doi.org/10.1080/09537280512331333057

Nudurupati, S. S., Bititci, U. S., Kumar, V., \& Chan, F. T. S. (2011). State of the art literature review on performance measurement. Computers \& Industrial Engineering, 60(2), 279-290. https://doi.org/10.1016/j.cie.2010.11.010

Nudurupati, S. S., Tebboune, S., \& Hardman, J. (2016). Contemporary Performance Measurement and Management (PMM) in Digital Economies. Production Planning \& Control, 27(3), 226-235. https:// doi.org/10.1080/09537287.2015.1092611

Otley, D. (1999). Performance Management: a Framework for Management Control Systems Research. Management Accounting Research, 10(4), 363-382. https://doi.org/10.1006/mare.1999.0115 
Otley, D. (2001). Extending the Boundaries of Management Accounting Research: Developing Systems for Performance Management. The British Accounting Review, 33(3), 243-261. https://doi.org/10.1006/ bare.2001.0168

Otley, D. (2003). Management Control and Performance Management: Whence and Whither?. British Accounting Review, 35(4), 309-326. https://doi.org/10.1016/j.bar.2003.08.002

Pavlov, A., \& Bourne, M. (2011). Explaining the Effects of Performance Measurement on Performance: An Organizational Routines Perspective. International Journal Operations \& Production Management, 31(1), 101-122. https://doi.org/10.1108/01443571111098762

Pekkola, S., \& Rantanen, H. (2014). Utilisation of Performance Measurement Information in Management: Top Manager Perspective. International Journal Business Performance Management, 15(1), 23-34. https:// doi.org/10.1504/IJBPM.2014.057879

Pekkola, S., Saunila, M., \& Rantanen, H. (2016). Performance Measurement System Implementation in a Turbulent Operating Environment. International Journal Productivity and Performance Management, 65(7), 947-958. https://doi.org/10.1108/IJPPM-01-2015-0018

Schneier, C. E., Shaw, D. G., \& Beatty, R. W. (1991). Performance Measurement and Management: A Tool for Strategy Execution. Human Resource Management, 30(3), 279-301. https://doi.org/10.1002/hrm.3930300302

Sharif, A. M. (2002). Benchmarking Performance Management Systems. Benchmarking: An International Journal, 9(1), 62-85. https://doi.org/10.1108/14635770210418588

Sidorova, Y., Arnaboldi, M., \& Radaelli, J. (2016). Social Media and Performance Measurement Systems: Towards a New Model?. International Journal Productivity and Performance Management, 65(2), 139-161. https:// doi.org/10.1108/IJPPM-06-2014-0084

Taticchi, P., Balachandran, K., \& Tonelli, F. (2012). Performance Measurement and Management Systems: State of the Art, Guidelines for Design and Challenges. Measuring Business Excellence, 16(2), 41-54. https:// doi.org/10.1108/13683041211230311

Thiel, G. G., Ensslin, S. R., Ensslin, L. (2017). Street Lighting Management and Performance Evaluation: Opportunities and Challenges. Lex Localis - Journal Local Self-Government, 15(2), 303-328. https:// doi.org/10.4335/15.2.303-328(2017)

Thomas, T. F. (2016). Motivating Revisions of Management Accounting Systems: Examination of Organizational Goals and Accounting Feedback. Accounting, Organizations and Society, 53, 1-16. https://doi.org/10.1016/ j.aos.2016.07.001

Tuomela, T. S. (2005). The Interplay of Different Levers of Control: A Case Study of Introducing a New Performance Measurement System. Management Accounting Research, 16(3), 293-320. https:// doi.org/10.1016/j.mar.2005.06.003

Valenzuela-Oyaneder, L., \& Maturana-Valderrama, S. (2016). A New Balanced Scorecard Approximation to Enhance Performance Management Systems of Chilean Wineries. Journal Wine Research, 27(1), 1-18. https:// doi.org/10.1080/09571264.2016.1141761

Valmorbida, S. M. I., \& Ensslin, S. R. (2017). Performance Evaluation of University Rankings: Literature Review and Guidelines for Future Research. International Journal of Business Innovation and Research, 14(4), 479-501. https://doi.org/10.1504/IJBIR.2017.087844

Van Camp, J., \& Braet, J. (2016). Taxonomizing Performance Measurement Systems' Failures. International Journal Productivity and Performance Management, 65(5), 672-693. https://doi.org/10.1108/IJPPM-03-2015-0054

Venkatesh, S., \& Ramachandran, S. (2014). Performance Measurement and Management System-Inter Company Case Study Approach-Tamilnadu, India. International Journal Information, Business and Management, 6(4), 87.

Waggoner, D. B., Neely, A. D., \& Kennerley, M. P. (1999). The Forces that Shape Organisational Performance Measurement Systems: An Interdisciplinary Review. International Journal Production Economics, 60-61(1), 53-60. http://www.sciencedirect.com/science/article/pii/S0925-5273(98)00201-1 
Wouters, M., \& Sportel, M. (2005). The Role of Existing Measures in Developing and Implementing Performance Measurement Systems. International Journal Operations \& Production Management, 25(11), 1062-1082. https://doi.org/10.1108/01443570510626899

Yadav, N., Sushil, \& Sagar, M. (2014). Revisiting Performance Measurement and Management: Deriving Linkages with Strategic Management Theories. International Journal Business Performance Management, 15(2), 87-105. https://doi.org/10.1504/IJBPM.2014.060146

\section{Notas}

* Artigo de revisão, proveniente de tese de doutorado, em desenvolvimento. Sem financiamento.

\section{Licencia Creative Commons CC BY 4.0}

Para citar este artigo: Martins, V. A., Rolim Ensslin, S. e Dutra, A. (2018). Avaliação de Desempenho Organizacional: trajetória das pesquisas internacionais por meio de paradigmas e teorias. Cuadernos de Contabilidad, 19(47), 94-116. https://doi.org/10.11144/Javeriana.cc19-47.pado 